\title{
Preparation and optical properties of $\mathrm{Eu}^{2+}$ and $\mathrm{Sm}^{3+}$ co-doped glass ceramic phosphors emitting white color by violet laser excitation
}

\author{
Shotaro NISHIURA ${ }^{\dagger}$ and Setsuhisa TANABE \\ Graduate School of Human and Environmental Studies, Kyoto University, \\ Yoshida nishonmatsu-cho, Sakyo-ku, Kyoto 606-8501
}

\begin{abstract}
$\mathrm{Eu}^{2+}$ and $\mathrm{Sm}^{3+}$ co-doped silicate glasses were prepared under reducing atmosphere in a system $\mathrm{SiO}_{2}-\mathrm{Al}_{2} \mathrm{O}_{3}-\mathrm{CaO}_{\text {and }}$ the glassceramics were obtained by heat-treatment at temperatures between 1000 and $1400^{\circ} \mathrm{C}$. Broad emission band were observed between 400 and $550 \mathrm{~nm}$ due to the $5 \mathrm{~d} \rightarrow 4 \mathrm{f}$ transition of $\mathrm{Eu}^{2+}$, as well as sharp emission peaks at $563,600,646$ and $713 \mathrm{~nm}$ due to the $4 \mathrm{f} \rightarrow 4 \mathrm{f}$ transition of $\mathrm{Sm}^{3+}$ in the samples. Emission color became white under ultraviolet or violet excitation for the glass ceramics heat-treated at above $1100^{\circ} \mathrm{C}$. Ceramming temperature dependence of the color coordinates, emission spectra were investigated and discussed with the precipitated crystal phases. We have successfully obtained the glass ceramic phosphor emitting white color, suitable for a white LED without organic resin for power illumination.
\end{abstract}

(-2008 The Ceramic Society of Japan. All rights reserved.

Key-words : White LEDs, Glass ceramics, Phosphor, Europium, Samarium

[Received June 11, 2008; Accepted September 11, 2008]

\section{Introduction}

In 1993, the high power output blue indium gallium nitride (InGaN) light-emitting diodes (LEDs) were developed. ${ }^{1), 2)}$ Then nitride and phosphide LEDs achieved light's three primary colors (RGB). These LEDs applied for solid state lighting such as displays and general illumination because they have high brightness, low electric consumption and long lifetime. White LEDs have also been studied to apply for general illumination. ${ }^{3)-6)}$ The most common white LEDs consist of blue LED-chip and YAG: Ce powder phosphor packed with organic resins. ${ }^{7)}$ The function of the phosphors in the white LEDs is to absorb the light emitted from ultraviolet or blue LED-chip and converts it into visible light. However, white LEDs have poor heat-resistance due to organic resins. The color of these resins change into yellow and cause degradation of phosphor and luminous intensity. ${ }^{8)}$ With increasing output power of LEDs for general illumination, this problem is becoming more and more serious. The commercial white LEDs also have low color rendering because these emission spectra are pseudo-white, which is a combination of blue (LED) and yellow emissions (YAG: Ce phosphor).

The glass ceramic phosphors doped with rare-earth ions are novel materials to improve these problems because they have efficient luminescence, excellent heat-resistance and ease of formability. ${ }^{9)}$ These materials are prepared by cerammization of a glass doped with rare-earth ions with a specific composition. The precipitated crystals in the glass matrix are visible phosphors, which can be used as a component of white LEDs, showing photoluminescence (PL), excited with blue or ultra violet (UV) LED.

The $\mathrm{Eu}^{2+}$-doped phosphors show broad emission band with very large optical cross sections by $4 \mathrm{f}^{6} 5 \mathrm{~d}^{1} \rightarrow 4 \mathrm{f}^{7}$ transition. ${ }^{10)}$ The emission color in oxide hosts is usually ranging from violet to

Corresponding author: S. Nishiura; E-mail: s.nishiura@nctdd. mbox.media.kyoto-u.ac.jp yellow, depending on the ligand field in them. The excitation and emission spectra can be varied by changing the host lattice or chemical composition. Because their typical emission spectra covers wide wavelength range of visible, the $\mathrm{Eu}^{2+}$ doped phosphors become one of the most important components in the phosphor-converting white LED.

$\mathrm{Sm}^{3+}$ doped phosphors show orange or red emission by $4 \mathrm{f} \rightarrow 4 \mathrm{f}$ transition, ${ }^{11)}$ which can improve color rendering in the wavelength band where many of the commercial white LEDs show low color rendering. One of the advantages of $\mathrm{Sm}^{3+}$ is its strong absorption peak at $405 \mathrm{~nm}$ where the external quantum efficiency of InGaN LEDs becomes the highest. Although the Sm ions can also take a divalent state, Sm(II), depending on the host composition and preparation condition, the tendency of reduction is much smaller than that of Eu(II) ions. ${ }^{12)}$ Therefore, it is possible to make glass and ceramic samples co-doped with $\mathrm{Eu}^{2+}$ and $\mathrm{Sm}^{3+}$ ions by choosing an appropriate reducing condition, which may lead to a phosphor material having an excellent color rendering index, CRI, including the red wavelength region.

In this study, we prepared $\mathrm{Eu}^{2+}$ and $\mathrm{Sm}^{3+}$ co-doped silicate glass ceramic phosphors and investigated the crystalline phase with X-ray diffraction. We also discuss excitation and emission spectra, the quantum yield and color coordinates of the emission of these samples.

\section{Experimental procedure}

Glass with composition of $30 \mathrm{SiO}_{2} \cdot 30 \mathrm{Al}_{2} \mathrm{O}_{3} \cdot 40 \mathrm{CaO}: 0.1 \mathrm{Eu}_{2} \mathrm{O}_{3}$, $0.1 \mathrm{Sm}_{2} \mathrm{O}_{3}$ was prepared by using $\mathrm{SiO}_{2}, \mathrm{Al}_{2} \mathrm{O}_{3}, \mathrm{CaCO}_{3}, \mathrm{Eu}_{2} \mathrm{O}_{3}$ and $\mathrm{Sm}_{2} \mathrm{O}_{3}$. $\mathrm{NH}_{4} \mathrm{Cl}$ was added as a flux at 5 mass\%. All the chemical powders were $99.9 \%-99.99 \%$ purity. Batches of about $25 \mathrm{~g}$ materials were well mixed in an alumina mortar. The mixed materials were first heated in an alumina crucible at $900^{\circ} \mathrm{C}$ for $1 \mathrm{~h}$ using an electric furnace. The crucible was placed in a larger alumina crucible that was filled with graphite powder to reduce $\mathrm{Eu}^{3+}$ into $\mathrm{Eu}^{2+}$. And then the mixed materials were melted at 
$1600^{\circ} \mathrm{C}$ for $1.5 \mathrm{~h}$ under the same condition. The melt was poured onto a pre-heated stainless-steel mold. The glasses obtained were annealed for $30 \mathrm{~min}$ at the glass transition temperature $\left(T_{\mathrm{g}}\right)$ determined by a differential scanning calorimeter (DSC) (Rigaku, Thermo plus, DSC8270) at a heating rate of $10^{\circ} \mathrm{C} / \mathrm{min}$. The annealed glasses (As-made glasses) were cut into $5 \mathrm{~mm} \times 5 \mathrm{~mm}$ $\times 7 \mathrm{~mm}$ size and then heat-treated at various temperatures between 1000 and $1400^{\circ} \mathrm{C}$ for $2 \mathrm{~h}$. X-ray diffraction (XRD) measurement was carried out to identify crystal phases of these samples with (Shimadzu XRD6000) using $\mathrm{Cu} \mathrm{K} \alpha$ radiation. The PL and photoluminescence excitation (PLE) spectra were measured by using a fluorescence spectrophotometer (Shimadzu, RF-5000). The total radiant flux of the PL were measured under $378 \mathrm{~nm}$ LD excitation (Nichia, NDHU110APAE3) by using an integrating sphere (Labsphere, LMS-100) which was connected to a CCD detector (Ocean Optics, USB2000) with an optical fiber. A standard halogen lamp (Labsphere, CLS-600) was used for calibration of this measurement system. With the power distribution spectrum of total flux obtained, the quantum yield (QY) of the samples was evaluated by the following equation,

Quantum yield (QY)

$$
=\frac{\text { Emission photon number }}{\text { Absoprtion photon number }} \times 100 \%,
$$

where the emission and the absorption photon number were calculated by integrating the photon distribution spectrum that was calculated from the spectral power distribution. In order to correct the effects of the secondary absorption by the reflection of excitation light from the inner wall of the sphere, the spectrum by indirect excitation was subtracted from the spectrum by direct excitation.

The color coordinates $(x, y)$ of CIE-1931 chromaticity diagram ${ }^{13)}$ were obtained under $378 \mathrm{~nm}$ LD excitation (Nichia, NDHU110APAE3) with a software (Ocean Optics, Spectra Suite) from the calibrated spectra obtained.

\section{Results}

The colors of glasses and glass ceramics prepared from the batch composition were yellow or yellowish white due to the $4 \mathrm{f}^{6} 5 \mathrm{~d}^{1} \leftarrow 4 \mathrm{f}^{7}$ absorption transition of $\mathrm{Eu}^{2+}$ in the violet to blue wavelength region. Surface crystallization was observed for the samples heat-treated above $1100^{\circ} \mathrm{C}$.

The DSC curve of the as-made glass is shown in Fig. 1. The $T_{\mathrm{g}}$ and the onset crystallization temperature $\left(T_{x}\right)$ were $860^{\circ} \mathrm{C}$ and $980^{\circ} \mathrm{C}$, respectively. One small exothermic peak was observed at $1280^{\circ} \mathrm{C}$. The X-ray diffraction patterns of these glass ceramics that were heat-treated between 1000 and $1400^{\circ} \mathrm{C}$ are shown in

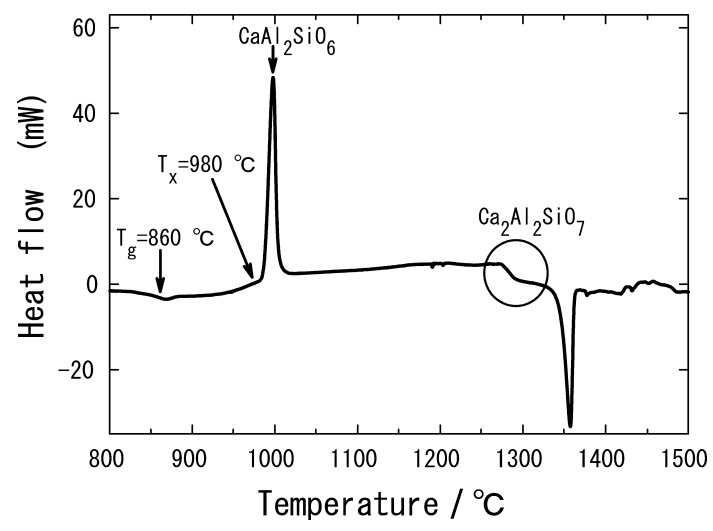

Fig. 1. DSC curve of $\mathrm{Eu}^{2+}-\mathrm{Sm}^{3+}$ co-doped glass.
Fig. 2. The $\mathrm{CaAl}_{2} \mathrm{SiO}_{6}$ and $\mathrm{Ca}_{2} \mathrm{Al}_{2} \mathrm{SiO}_{7}$ crystals were precipitated at temperature range of $1000-1200^{\circ} \mathrm{C}$ and $1300-1400^{\circ} \mathrm{C}$, respectively. The heat-treatment temperature variations of PL spectra of the as-made glass and the glass ceramics under $378 \mathrm{~nm}$ excitation are shown in Fig. 3. The broad emission bands peaking between $420 \mathrm{~nm}$ and $520 \mathrm{~nm}$ originate from the $4 \mathrm{f}^{6} 5 \mathrm{~d}^{1} \rightarrow 4 \mathrm{f}^{7}$ transition of $\mathrm{Eu}^{2+}$. The narrow emission bands peaked at $563 \mathrm{~nm}, 600 \mathrm{~nm}, 646 \mathrm{~nm}$ and $713 \mathrm{~nm}$ originate from the ${ }^{4} \mathrm{G}_{5 / 2} \rightarrow{ }^{6} \mathrm{H}_{5 / 2},{ }^{4} \mathrm{G}_{5 / 2} \rightarrow{ }^{6} \mathrm{H}_{7 / 2},{ }^{4} \mathrm{G}_{5 / 2} \rightarrow{ }^{6} \mathrm{H}_{9 / 2}$ and ${ }^{4} \mathrm{G}_{5 / 2} \rightarrow{ }^{6} \mathrm{H}_{11 / 2}$ transition of $\mathrm{Sm}^{3+}$, respectively. The heat-treatment temperature variations of PLE spectra of the as-made glass and the glass ceramics are shown in Fig. 4. The $\lambda_{\mathrm{em}}$ is the monitoring wavelength of $\mathrm{Eu}^{2+}$ emission peak. The peak wavelenghs of broad excitation bands were located between $330 \mathrm{~nm}$ and $420 \mathrm{~nm}$. The peaks of the glass and the glass ceramics heat-treated at 1000$1100^{\circ} \mathrm{C}$ and $1200-1400^{\circ} \mathrm{C}$ were 420,330 and $360-380 \mathrm{~nm}$, respectively. The Stokes shifts of the samples were $70 \mathrm{~nm}$ for asmade, $100 \mathrm{~nm}$ for $1000-1100^{\circ} \mathrm{C}$ and $140 \mathrm{~nm}$ for $1200-1400^{\circ} \mathrm{C}$.

The QY of the samples under $378 \mathrm{~nm}$ excitation is plotted as a function of ceramming temperature in Fig. 5. The maximum value of QY was $11 \%$ at $1000^{\circ} \mathrm{C}$. The QY values of the samples heat-treated above $1100^{\circ} \mathrm{C}$ were approximately $4 \%$.

The color coordinates of the samples under $378 \mathrm{~nm}$ excitation are plotted in the chromaticity diagram in Fig. 6. All the samples

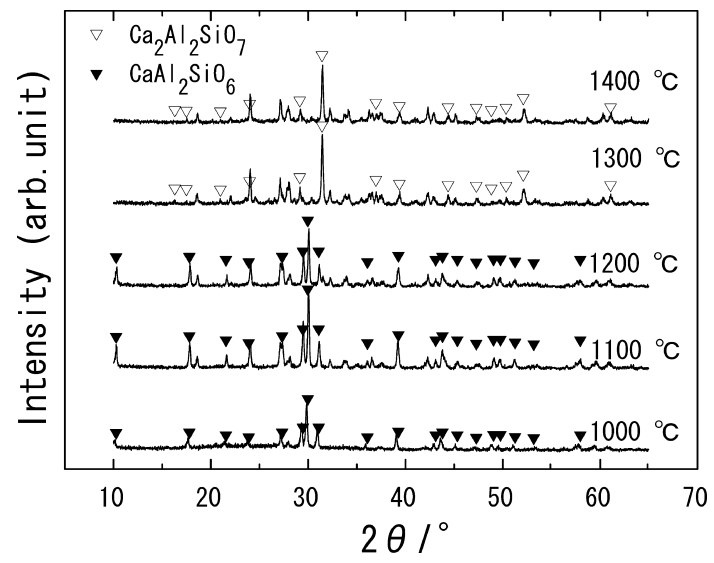

Fig. 2. X-ray diffraction patterns of $\mathrm{Eu}^{2+}-\mathrm{Sm}^{3+}$ co-doped glass ceramics heat treated at $1000-1400^{\circ} \mathrm{C}$.

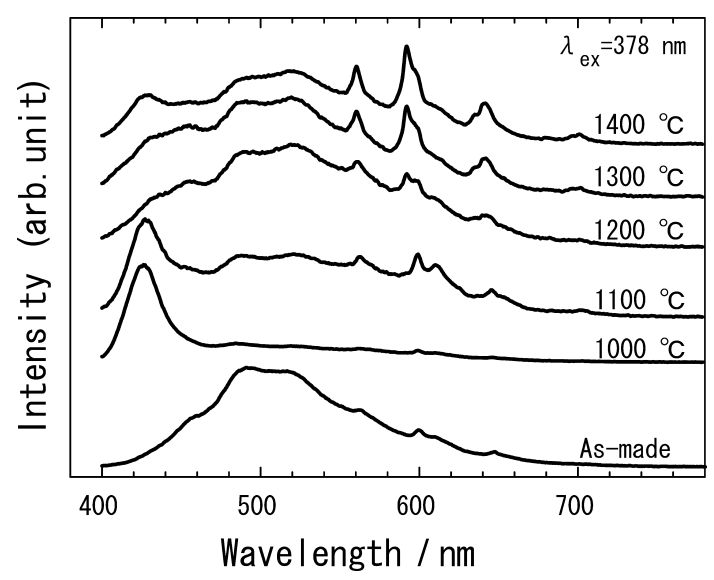

Fig. 3. Heat-treatment temperature variations of photoluminescence spectra o $\mathrm{Eu}^{2+}-\mathrm{Sm}^{3+}$ co-doped glass and glass ceramics under excitation at $378 \mathrm{~nm} \mathrm{LD}$. 


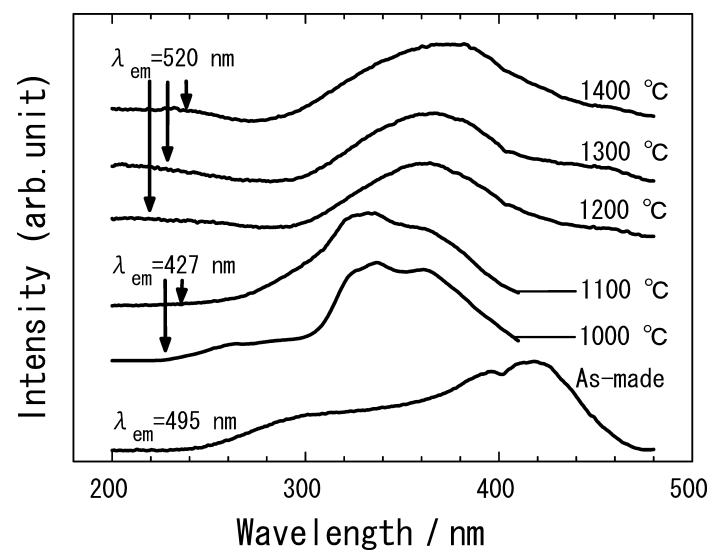

Fig. 4. Heat-treatment temperature variations of photoluminescence excitation spectra of $\mathrm{Eu}^{2+}-\mathrm{Sm}^{3+}$ co-doped glass and glass ceramics at emission peak wavelength of $\mathrm{Eu}^{2+}$.

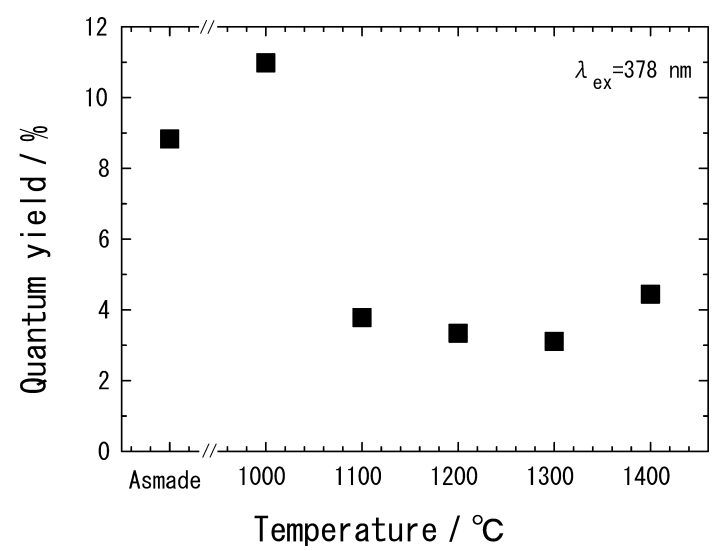

Fig. 5. Heat-treatment temperature dependence of quantum yield of $\mathrm{Eu}^{2+}-\mathrm{Sm}^{3+}$ co-doped glass and glass ceramics under excitation at $378 \mathrm{~nm}$ LD.

except that heat-treated at $1000^{\circ} \mathrm{C}$ were in the range of $(x, y)=$ $(0.27-0.33,0.3-0.4)$ corresponding to white or greenish white.

\section{Discussion}

As indicated from Fig. 1 and Fig. 2, the exothermic peaks of 1000 and $1280^{\circ} \mathrm{C}$ in Fig. 1 correspond to the precipitation of $\mathrm{CaAl}_{2} \mathrm{SiO}_{6}$ and $\mathrm{Ca}_{2} \mathrm{Al}_{2} \mathrm{SiO}_{7}$, respectively. Both crystals, doped with $\mathrm{Eu}^{2+}$ ions, show broad emission spectra in the visible range.

As shown in Fig. 3 and Fig. 4, the PL and PLE spectra of $\mathrm{Eu}^{2+}$ were largely changed between the glass and the glass ceramics. This is probably because the $\mathrm{Eu}^{2+}$ was doped into the precipitated aluminosilicate crystal phase. The coordination environment of $\mathrm{Eu}^{2+}$ should be different between silicate glass matrix and crystal. ${ }^{10)}$ The emissions of $\mathrm{Eu}^{2+}$ and $\mathrm{Sm}^{3+}$ are originated from the $5 \mathrm{~d} \rightarrow 4 \mathrm{f}$ transition and the $4 \mathrm{f} \rightarrow 4 \mathrm{f}$ transition, respectively. The $4 \mathrm{f}$ orbital is shielded from the surroundings by the filled $5 \mathrm{~s}^{2}$ and $5 \mathrm{p}^{6}$ orbitals. On the other hand, the $5 \mathrm{~d}$ orbital is the outershell orbital. Therefore the influence of coordination environment in $5 \mathrm{~d} \rightarrow 4 \mathrm{f}$ transition is much larger than that in the $4 \mathrm{f} \rightarrow 4 \mathrm{f}$ transition. The change of coordination environment influences optical properties of $\mathrm{Eu}^{2+}$ than that of $\mathrm{Sm}^{3+}$.

From Fig. 3, the peak wavelengths of $\mathrm{Eu}^{2+}$ were changed from $420 \mathrm{~nm}$ to $520 \mathrm{~nm}$ by ceramming at $1000-1200^{\circ} \mathrm{C}$, which correspond to the precipitation temperature of $\mathrm{CaAl}_{2} \mathrm{SiO}_{6}$. The color

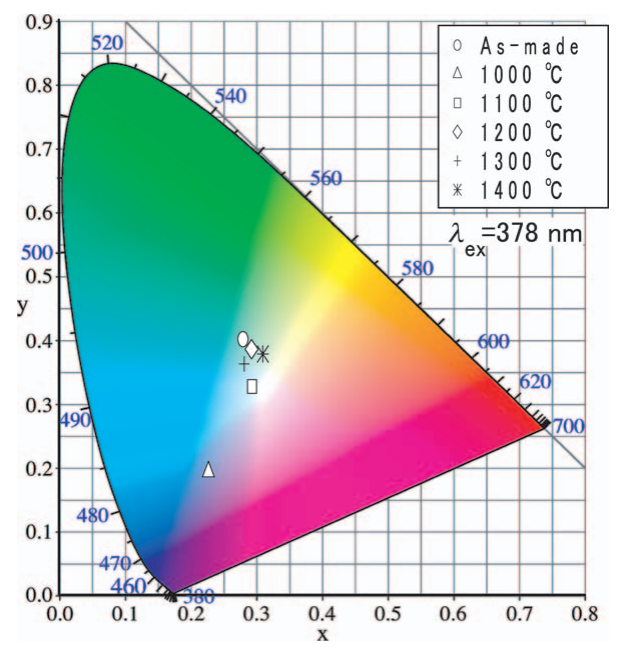

Fig. 6. Chromaticity color coordinates of $\mathrm{Eu}^{2+}-\mathrm{Sm}^{3+}$ co-doped glass and glass ceramics.

of sample's surface was white, while the inside was yellow. Actually, in the samples heat-treated at $1100-1400^{\circ} \mathrm{C}$ the surface crystallization occurred. The relative intensity of $\mathrm{Sm}^{3+}$ was increased with increasing heat-treatment temperature and the emission of $\mathrm{Eu}^{2+}$ between $470 \mathrm{~nm}$ and $500 \mathrm{~nm}$ was decreased.

From Fig. 4, the excitation peak wavelengths of the glass ceramics were shorter than that of the glass.

As shown in Fig. 6, the samples except that heat-treated at $1000^{\circ} \mathrm{C}$ showed white or greenish white emission. Although the $\mathrm{QY}$ of the glass ceramics cerammed at above $1100^{\circ} \mathrm{C}$ are still only $4 \%$, if the relative emission of $\mathrm{Sm}^{3+}$ is increased, the color coordinates shift to red region, resulting in warm white. In the lighting technologies including white LEDs for the next generation, achievement of warm white color having low correlated color temperatures, CCT, around $3000 \mathrm{~K}$, are becoming an important issue. Therefore, the optimization of the intensity ratio of $\mathrm{Sm}^{3+} / \mathrm{Eu}^{2+}$ can be one of the simple routes to solve this important issue.

Further improvement of QY is expected by optimization of preparation conditions of glass and glass ceramics in this codoped silicate system.

\section{Conclusions}

$\mathrm{Eu}^{2+}$ and $\mathrm{Sm}^{3+}$ co-doped silicate glass ceramic phosphors were obtained by heat-treating a glass of $\mathrm{SiO}_{2}-\mathrm{Al}_{2} \mathrm{O}_{3}-\mathrm{CaO}$ system. The DSC and XRD results showed that $\mathrm{CaAl}_{2} \mathrm{SiO}_{6}$ and $\mathrm{Ca}_{2} \mathrm{Al}_{2} \mathrm{SiO}_{7}$ crystals were precipitated at $1000^{\circ} \mathrm{C}$ and $1280^{\circ} \mathrm{C}$, respectively. The emission wavelengths of $\mathrm{Eu}^{2+}$ in the glass ceramics were changed from that of the glass because $\mathrm{Eu}^{2+}$ was doped into the crystal phases. The emission intensity of $\mathrm{Sm}^{3+}$ was increased with increasing heat treatment temperature. The convolution of emissions from $\mathrm{Eu}^{2+}$ and $\mathrm{Sm}^{3+}$ resulted in white emission. The $\mathrm{Eu}^{2+}$ and $\mathrm{Sm}^{3+}$ co-doped glass ceramic phosphors showed a potential as phosphor candidate for white LEDs having an excellent CRI and low CCT.

\section{References}

1) S. Nakamura, M. Senoh and T. Mukai, Appl. Phys. Lett., 62, 2390-2392 (1993).

2) D. Malakoff, Science, 296, 1782 (2002).

3) P. Schlotter, R. Schmidt and J. Schneider, Appl. Phys. A: Mater. Sci. Process., 64, 417-418 (1997). 
4) T. Nishida, T. Ban and N. Kobayashi, Appl. Phys. Lett., 82, 3817-3819 (2003).

5) H. S. Jang and D. Y. Jeon, Appl. Phys. Lett., 90, 041906 (2007).

6) E. F. Schubert and J. K. Kim, Science, 308, 1274-1278 (2005).

7) Y. Narukawa, I. Niki, K. Izuno, M. Yamada, Y. Murazki and T. Mukai, Jpn. J. Appl. Phys., 41, L371-L373 (2002).

8) F. M. Steranka, J. Bhat, D. Collins, L. Cook, M. G. Craford, R. Fletcher, N. Gardner, P. Grillot, W. Goetz, M. Keuper, R. Khare, A. Kim, M. Krames, G. Harbers, M. Ludowise, P. S. Martin, M. Misra, G. Mueller, R. Mueller-Mach, S. Rudaz, Y. C. Shen, D. Steigerwald, S. Stockman, S. Subramanya, T.
Trotter and J. J. Wierer, Phys. Stat. Sol. (a), 194, 380-388 (2002).

9) S. Tanabe, S. Fujita, A. Sakamoto and S. Yamamoto, Ceram. Trans., 173, 19-25 (2006).

10) G. Blasse and B. C. Grabmaier, "Luminescent Materials," Springer, Berlin (1994) pp. 46-50.

11) U. Rambabu, P. K. Khanna and S. Buddhudu, Mater. Lett., 38 , 121-124 (1999).

12) L. J. Nugent, R. D. Baybarz, J. L. Burnett and J. L. Ryan, J. Phys. Chem., 73, 1177-1178 (1969).

13) D. Malacara, "Color Vision and Colorimetry:Theory and Applications," SPIE Press (2002) pp. 49-75. 